\title{
THE 1994 ICCA JOURNAL AWARD
}

\author{
The Board of ICCA
}

The Board of ICCA is happy to announce the winner of the 1994 ICCA Journal Award for the best paper in this Journal by a first-time author. For the period April 1, 1993 to March 31, 1994, covering the issues Vol. 16, No. 2 up to and including Vol. 17, No. 1, this award has, on the recommendation of the ICCA Journal Board members, been granted to Christian Donninger for his article: "Null Move and Deep Search", ICCA Journal, Vol. 16, No. 3, pp. 137-143. Christian Donninger is entitled to three Volumes of his choice of the Journal's back issues. A brief scientific biography of the winner, an intrinsic part of the Award, is published below and has been based on a biobibliographical essay provided by the Award winner.

\section{CHRISTIAN DONNINGER: A SCIENTIFIC BIOGRAPHY}

Christian Donninger was born in 1957 in the Austrian province of Upper Austria (Oberösterreich). His parents are typically working class. He moved to Vienna in 1976 to study Mathematics and Physics, financing his studies by private tutoring of Mathematics and by part-time programming. After finishing his studies with an M.Sc. in both disciplines and a Ph.D. in Mathematics, he worked as an Assistant Professor for Statistics at the Vienna Institute for Advanced Studies. In this area he regards his publication Spatial Autocorrelation Among Errors and the Relative Efficiency of OLS in the Linear Regression Model in the highly-renowned Journal of the American Statistical Association (June 1987) as the high crown of his achievement.

In 1987 he said farewell to the ivory tower and started work in Austrian software companies. From 1989 to 1992, he was a consultant developing an Environmental Control Simulation package (ECOSIM) at the European Space Technology Centre (ESTEC) in Noordwijk, the Netherlands (ECOSIM - An Environmental Control Simulation Software, SAE Technical Paper Series, 911543, San Francisco, 1991). As a cure for his home-sickness, he started chess programming as a hobby in 1990.

Having unexpectedly reached the $4^{\text {th }}$ place at the World Microcomputer Chess Championship 1993 in Munich with his program NIMZO-II he quitted regular occupation and became a computer-chess professional. In addition, he also serves as a lecturer in the specialized field of computer chess in the University of Linz, Upper Austria. As to his publications, he is a co-author of a book on computer chess to be published in the summer of 1995. Moreover, he regularly publishes in popular magazines not only on computer chess, but also about more general topics, such as the impact of modern technology and of the scientific view of the world on social life and on the human soul. He is especially critical on what are - in his view - the inhuman and, as it fortunately happens, the unrealistic goals in AI.

Currently he is working on an efficient method to extract, under tournament conditions, knowledge and/or strategic plans from games played by strong human beings. This method will be incorporated in the commercial program NIMZO-III. Christian Donninger is also highly interested in writing a massively-parallel chess program, due to what he regrets as the dearth of the lack of available resources and of interest in his home country, these plans are Platonic only. 